\title{
Non-Linear Model to Describe Growth Curves of Commercial Turkey in the Tropics of Mexico
}

\section{-Author(s)}

\section{Segura-Correa $\mathrm{JC}^{\mathrm{I}}$ \\ Santos-Ricalde $\mathrm{RH}^{\prime}$ \\ Palma-Ávila I'}

Campus de Ciencias Biológicas y Agropecuarias, Universidad Autónoma de Yucatán Km. 15.5 carretera Mérida-Xmatkuil, A.P.4116, Itzimná, Mérida, Yucatán, México.

\section{nail Address}

Corresponding author e-mail address José C. Segura-Correa

Campus de Ciencias Bilologícas y Agropecuarias, Km 15.5 carretera Merida-Xmatkuil, Mérida, Yucatán, México.

Code: 97315

Email: jose.segura@correo.uady.mx

\section{- Keywords}

Bertalanffy, Gomperz, Logistic, body weight.

\section{ABSTRACT}

The objective of this study was to select the best non-linear model that fits the growth curve of turkeys managed under the tropical conditions of Southern Mexico. Data from 481 Hybrid converter turkeys (236 females and 245 males) reared under commercial conditions typical of that region were used. Turkeys were given ad libitum access to feed and water. Body weight was weekly recorded from 1 day to 23 weeks of age. Five non-linear mathematical models (Brody, Gompertz, Logistic, von Bertalanffy and Richards) were chosen to describe the age-weight relationship. The Brody and Richards' models fail to converge. The best fitting model was chosen based on the average prediction error (APE); the multiple determination coefficient $R^{2}$ and the Akaike information criterion (AIC). In both sexes, von Bertalanffy and Gompertz were the best models. The highest estimates of parameter $A$ (mature weight) for both females and males were obtained with the von Bertalanffy model followed by the Gompertz and Logistic. The estimates of A were higher for males than for females. The highest estimates of parameter $k$ (rate of maturity) for both females and males were, in decreasing order for the Logistic, Gompertz, and von Bertalanffy models. k values for female turkeys was higher than for males. The age at the point of inflection and body weight at the age of point of inflection varied with the model used. The largest values of $T_{1}$ and $W_{1}$ corresponded to the Logistic model. Between sexes, the largest $T$, and $W$ values corresponded to males. The best models to describe turkey growth were the von Bertalanffy and Gompertz models, because it presented the highest APE, $R^{2}$ and AIC values.

\section{INTRODUCTION}

Growth is the result of an animal gaining weight with time until it reaches maturity (Porter et al., 2010). The knowledge of the growth curve of turkeys is important to develop management practices that could help increase their productivity. The growth of turkeys, as that of other domestic animals, is characterized by a sigmoid-type curve with three phases: initial slow growth, a phase of pronounced acceleration, and a period of deceleration, until mature weight is reached (Lawrence \& Fowler, 2012). In the tropics, the live performance of turkeys is influenced by extreme conditions of the tropical environment.

The growth of domestic animals may be described by several non-linear models (NLM), as a function of time and a number of parameters that can have a biological interpretation. The Gompertz, von Bertalanffy, Brody, Richards, and Logistic growth models are commonly used to explain animal growth. In addition, based on the parameters of the growth models, other indicators can be derived, such as age and weight at the point of inflection (Takma et al., 2004; Ersoy et al., 2006). On the other hand, the parameter estimates derived 
from NLM may be used as selection criteria within a turkey population with the aim of modifying the shape of the growth curve (Mignon-Grasteau et al., 1999; Mignon-Grasteau et al., 2000). The growth curve may be affected by breed, sex, feeding program (Thornley \& France, 2007), lighting program (Mendeş et al., 2005), and rearing period, making it important to determine the best model under specific conditions. There are few papers that describe the growth curve of turkeys, and none under the tropical conditions of Mexico. The objective of this study was to select the NLM that best fits turkey growth managed under the tropical conditions of Southern Mexico.

\section{MATERIAL AND METHODS}

Data from 481 Hybrid converter turkeys (236 females and 245 males) were used in this study. Birds were bought from a commercial hatchery and were assumed not to be related by kinship. The turkeys were raised on a deep litter system from June to November of 2013 under commercial conditions typical of that region. All the birds were individually identified and their sex determined at 10 weeks of age by phenotype. Turkeys were given ad libitum access to feed and water. Turkeys (males and females) were fed even diets. Diet1 contained28\% crude protein (CP) and $3020 \mathrm{kcal}$ metabolizable energy (ME)/kg; diet2, with $26 \% \mathrm{CP}$ and $3100 \mathrm{kcal} \mathrm{ME} / \mathrm{kgfed}$ from week 5 to 8; diet3, with 24\% CP and $3150 \mathrm{kcal}$ ME/kgfed in weeks 9 and10; diet4 with 22\% CP and $3250 \mathrm{kcal} \mathrm{ME} / \mathrm{kgfed}$ in weeks11 and 12; diet5 with 20\% CP and $3350 \mathrm{kcal}$ ME/kgfed in weeks 13 and 14; diet6 with $18 \%$ CP and $3350 \mathrm{kcal} \mathrm{ME} / \mathrm{kgfed}$ from weeks 15 to 18; and diet 7 with $16 \% \mathrm{CP}$ and $2800 \mathrm{ME} \mathrm{kcal} / \mathrm{kg}$ from weeks 19 to 23. Body weights were recorded weekly from 1 day to 23 weeks of age.

Five non-linear mathematical models (Brody, Gompertz, Logistic, von Bertalanffy and Richards) were chosen to describe age-weight relationship in turkeys.

The non-linear models used to describe the turkeys' growth curves were:

Brody: $y=A^{*}\left(1-b^{*} \exp \left(-k^{*} t\right)\right)^{\prime}$

Gompertz: $y=A * \exp \left(-b^{*} \exp \left(-k^{*} t\right)\right)$

Logistic: $y=A /\left(1+b^{*} \exp \left(-k^{*} t\right)\right.$

von Bertalanffy: $y=A^{*}\left(1-b^{*} \exp \left(-k^{*} t\right)^{3}\right.$

Richards: $y=A^{*}\left(1-b^{*} \exp \left(-k^{*} t\right)\right)^{m}$

Where

$y=$ turkey weight at time $(t)$

$A=$ mature or asymptotic weight $\mathrm{b}=$ integration constant

$k=$ maturity rate

$\mathrm{t}=$ turkey age

$\mathrm{m}=$ shape parameter that determines the time and the weight at inflection point.

Age at point of inflection $\left(T_{1}\right)$ and body weight at the age at point of inflection $\left(\mathrm{W}_{\text {, }}\right.$ ) of the Gompertz, Logistic and von Bertalanffy models were estimated as follows: $\ln (b) / k$ and $A / e ; \ln (b) / k$ and $A / 2$; and $\ln (3 b) / k$ and $A * 8 / 27$, respectively (Goshu \& Koya, 2013); where $\mathrm{e}=2.71828$, the base of the natural logarithms.

The best fitting model was chosen based on the following criteria: 1) the average prediction error (APE), calculated by the differences between the observed and the estimated weights at all weightings per individual and of all the individuals; 2 ) the multiple determination coefficient $R^{2}=(1-(S S E / S S T))$, estimated based on the sum of squares of the error (SSE) and the corrected total sum of squares (SST); 3 ) the Akaike information criterion (AIC), with $\mathrm{AIC}=\mathrm{N} * \ln (\mathrm{SSE} /$ $N)+(2 p+1)$ estimated based on the sum of squares of the error (SSE), the number of observations (N) and the number of parameters ( $p$ ) in the model; and 4)graphic analysis of the observed and estimated curves. The model with APE value close to cero, the lowest AIC, and the highest $\mathrm{R}^{2}$ was considered the best fit model.

All growth models were fitted to the body weight and age data of the turkeys, using the NLIN procedure of the SAS software. The Marquardt iterative procedure was used to reduce the residuals and improve the goodness of fit (SAS, 2010).

\section{RESULTS AND DISCUSSION}

The Gompertz, von Bertalanffy, Richards, Brody and Logistic growth models were evaluated as to their ability to describe the relationship between body weight and age in growing turkeys (males and females). The estimated NLM growth curves and the curve of observed body weights for females and males are shown in Figures 1 and 2, and therefore, the results of the Brody and Richards' curves are not shown, because those models fail to converge, and they were dropped from further analysis. Porter et al. (2010) also found that the Richards model fail to converge in Hybrid turkey females.

The von Bertalanffy model best fit the data of turkeys of both sexes, followed closely by the Gompertz model (Table 1). This similarity indicates that the growth data are well described by the two models. The differences were that von Bertalanffy model underestimate female 
body weight in $42 \mathrm{~g}$ and male body weight in $21 \mathrm{~g}$ at 1 day of age, whereas the Gompertz model over estimated female and male body weights in $62 \mathrm{~g}$ and $33 \mathrm{~g}$, respectively at the same age. The Gompertz model also underestimated female and male body weights in 119 and in $220 \mathrm{~g}$, respectively, at 23 weeks of age (Figures 1 and 2).

Table 1 - Criterion values for three non-linear models.

\begin{tabular}{lccc}
\hline & \multicolumn{3}{c}{ Model } \\
\cline { 2 - 4 } Criterion & Gompertz & Logistic & von Bertalanffy \\
\hline Females & & & \\
R $\left.^{2} \%\right)$ & 99.32 & 99.10 & 99.35 \\
APE & -0.0162 & -0.0654 & 0.0067 \\
AIC & -6271 & -4915 & -6439 \\
Males & & & \\
$R^{2}$ & 98.96 & 98.70 & 99.0 \\
APE & -0.0345 & -0.1012 & -0.0034 \\
AIC & -1510 & -422 & -1728 \\
\hline
\end{tabular}

$\mathrm{R}^{2}=$ Coefficient of determination; $\mathrm{APE}=$ average prediction error; $\mathrm{AIC}=$ Akaike information criterion.

Based on the criteria established to compare the models, the best fit of the von Bertalanffy and the Gompertz models indicates that they can be used to model the growth curve of Hybrid turkey reared under the management conditions of tropical southern Mexico. These results agree with the findings of Tholon \& Queiroz (2007) in tinamous (Rhynchotus rufescens), when comparing the von Bertalanffy, Gompertz, Logistic, Brody and quadratic-quadratic-quadratic segmented polynomial models. Sengul \& Kiraz (2005) found that the Morgan-Mercer-Floding (MMF) model fitted better the data of Large White turkeys, followed by the Gompertz, Logistic, and Richards models. Pérez-Lara et al. (2013) verified that the polynomial

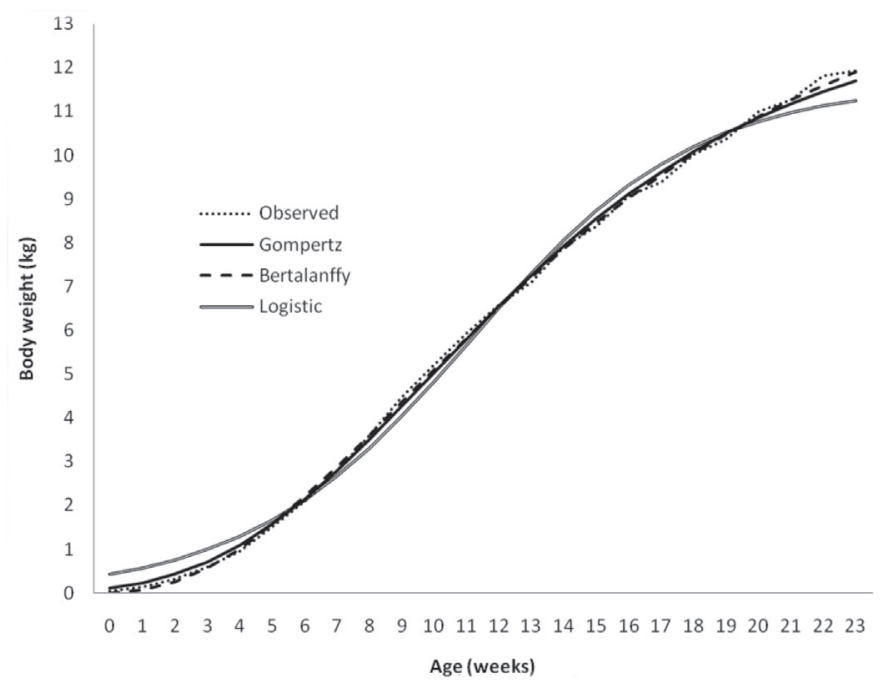

Figure 1 - Growth curves for female turkey using three non-linear models and observed data regression of the fourth degree described better the growth curve of native Mexican turkeys than the Richards model. Ersoy et al. (2006) applied the Richards model to describe the growth data of Bronze turkeys, because the preliminary analyses showed that this model was more effective than the Gompertz, Logistic, and von Bertalanffy models. Porter et al. (2010) found that the Morgan model fitted better growth data of turkey hens, followed by the von Bertalanffy and the Gompertz models. Differences among models could be partially explained by the species or type of turkey breed used and the rearing period of studied. For example, Sengul \& Kiraz (2005) studied Large White turkeys between 0 and 18 weeks of age; Pérez Lara et al. (2013) non-commercial Mexican turkeys from 0 to 55 weeks of age; Porter et al. (2010) Hybrid Large White turkey hens from 0 to 30 weeks of age, and Ersoy et al. (2006) studied the growth curve of Bronze turkeys from 11 to 24 weeks of age.

Parameter estimates of the growth curve models of male and female Hybrid turkeys are shown in Table 2. The highest estimates of parameter A (mature weight) for both females and males were obtained with the von Bertalanffy model followed by the Gompertz and the Logistic models. Mature or asymptotic weight (A) estimates for the three models that converged was higher for males than for females, indicating that male turkeys matured more slowly and it took more time to reach mature body weight than female turkeys (Table 2). The highest A value was obtained by the von Bertalanffy model and the lowest by the Logistic model, as previously reported by Tholon \& Queiroz (2007) in tinamous. In turkeys, Segul \& Kiraz (2005) found lower A value with the Logistic model in

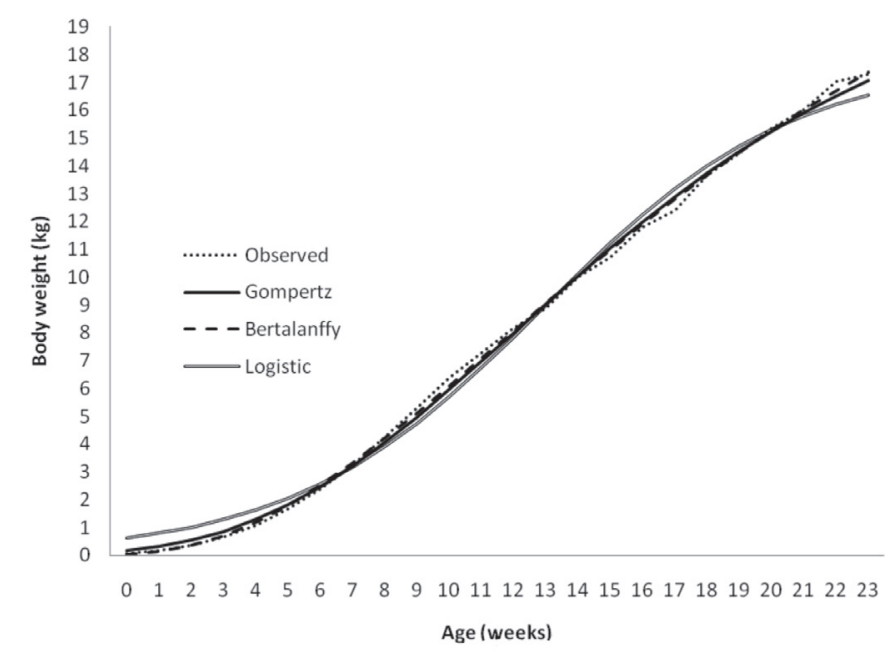

Figure 2 - Growth curves for male turkey using three non-linear models and observed data 
comparison with the Gompertz model. These results indicate that different models predict different mature body weights in turkeys.

Table $\mathbf{2}$ - Parameter estimates of the growth models for males and females turkeys under the tropical conditions of southern Mexico.

\begin{tabular}{lccc}
\hline & \multicolumn{3}{c}{ Model } \\
\cline { 2 - 4 } Parameter* & Gompertz & Logistic & von Bertalanffy \\
\hline Females & \multicolumn{3}{c}{} \\
$\mathrm{A}(\mathrm{kg})$ & $13.23 \pm 0.061$ & $11.62 \pm 0.038$ & $14.63 \pm 0.089$ \\
$\mathrm{~b}$ & $4.72 \pm 0.037$ & $25.49 \pm 0.412$ & $0.934 \pm 0.006$ \\
$\mathrm{k}$ (kg/week) & $0.159 \pm 0.001$ & $0.290 \pm 0.002$ & $0.115 \pm 0.001$ \\
$\mathrm{~T}_{1}($ weeks) & 9.78 & 11.17 & 8.97 \\
$\mathrm{~W}_{1}(\mathrm{~kg})$ & 4.87 & 5.81 & 4.34 \\
Males & & & \\
$\mathrm{A}(\mathrm{kg})$ & $21.67 \pm 0.170$ & $17.76 \pm 0.086$ & $25.88 \pm 0.297$ \\
$\mathrm{~b}$ & $4.73 \pm 0.038$ & $28.22 \pm 0.482$ & $0.907 \pm 0.005$ \\
$\mathrm{k}(\mathrm{kg} /$ week $)$ & $0.130 \pm 0.001$ & $0.259 \pm 0.002$ & $0.086 \pm 0.001$ \\
$\mathrm{~T}_{1}($ weeks) & 11.95 & 12.92 & 11.60 \\
$\mathrm{~W}_{1}(\mathrm{~kg})$ & 7.97 & 8.88 & 7.67 \\
\hline
\end{tabular}

${ }^{*} \mathrm{~A}=$ Body weight at maturity; $b=$ integration constant; $\mathrm{k}=$ relative growth coefficient or maturity index; $\mathrm{T}_{1}=$ age at inflection point; $\mathrm{W}_{1}=$ body weight at age of inflection point.

The highest estimates of parameter $b$ for females and males were obtained in the Logistic model, followed by the Gompertz and the von Bertalanffy models. The difference between sexes is probably due to the dependence of this parameter on the ratio between weight at hatch (day 1) and mature weight in each model, and therefore, it is more influenced by the model used than by the difference between sexes.

The $k$ parameter represents the maturation rate, that is, the growth rate to achieve mature weight from initial weight. The higher the $k$ value, the faster the animal achieves its mature (asymptotic) weight. The Logistic model estimated the highest $k$ value for both females and males (0.290 and 0.259 kg/week, respectively) and the lowest was obtained by the von Bertalanffy model ( 0.115 and $0.086 \mathrm{~kg} /$ week). Sengul \& Kiraz (2005), in Large White turkeys, also obtained the highest $k$ values using the Logistic model $(-0.27$ and -0.26 for both females and males, respectively) compared with the Gompertz and the Richards models. In Bronze turkey, Ersoy et al. (2006) obtained k values of 0.39 and $0.24 \mathrm{~kg} /$ week for females and males, respectively. Tholon \& Queiroz (2007), in tinamous, determined higher $k$ values with the Logistic model $(0.037 \mathrm{~kg} /$ day $)$, followed by the Gompertz $(0.050 \mathrm{~kg} /$ day), the von Bertalanffy (0.005 kg/day) and the Brody $(0.003 \mathrm{~kg} /$ day) models.

The point of inflection, at which the growth rate is maximum, provides an estimate of age and weight at puberty. This means that, under the conditions of the present study, male turkeys reached puberty later and at heavier body weights than female turkeys. The age at the point of inflection and body weight at the age of point of inflection of females and males were 8.97 weeks and $4.34 \mathrm{~kg}$, and 11.60 weeks and $7.67 \mathrm{~kg}$, respectively (Table 2 ). These results agree with those of Ersoy et al. (2006) in American Bronze turkeys, and those by Pérez-Lara et al.(2013) in Mexican native turkeys, who observed higher body weight in males than in females, at 55 weeks of age. However, Segul \& Kiraz (2005), in Large White turkeys, found higher A values for females than for males using the Gompertz model, which does not make any biological sense for turkeys, as males are normally heavier than females at maturity.

The knowledge of the growth curve is economically important because it can be used to determine the optimal age at slaughter and to take advantage of the period when the animals have reached maximum growth rate (Agudelo et al., 2008). The point of inflection indicates the time when acceleration of growth ceases (Goshu \& Goya, 2013) and initial weight $\left(W_{1}\right)$ is a proportional part of the body weight at maturity. According to the results from the present study (Table 2), $W$, represents $36.8 \%$ of the mature body weight of females by the Gompertz model, $45.7 \%$ by the Logistic model, and $29.7 \%$ by the von Bertalanffy model. For males, $\mathrm{W}$, represents $36.8 \%, 68.7 \%$, and $29.6 \%$ of their mature body weight, in the Gompertz, Logistic and von Bertalanffy models, respectively.

The results of this study are useful to define feeding programs for this genetic line (Hybrid converter), and because of differences in growth, it is recommended rear males separately from females, and to change feed formula, according to the von Bertalanffy model, at 8.97 weeks for females and 11.60 weeks for males. That idea is supported by the maximum estimated body weight, which may be additional8.44 $\mathrm{kg}$ for males compared with females.

In conclusion, based on the $\mathrm{R}^{2}, \mathrm{AIC}$, and APE values and on the observation of the growth curves, the best fit of the data was obtained with the von Bertalanffy and the Gompertz models. This information may support making decisions relative to the breeding and marketing of turkeys.

\section{ACKNOWLEDGEMENTS}

The authors wish to thank the turkey farm "Paraiso" for providing the animals for this study. 
Segura-Correa JC, Santos-Ricalde RH,

Palma-Ávila I

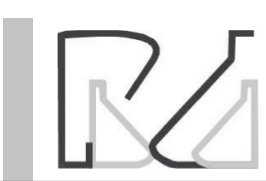

Non-Linear Model to Describe Growth Curves of Commercial Turkey in the Tropics of Mexico

\section{REFERENCES}

Agudelo-Gómez DA, Cerón-Muñoz MF, Restrepo-Betancur LF. Modelación de las funciones de crecimiento aplicadas a la producción animal. Revista Colombiana de Ciencia Pecuaria 2008;21(1):39-51.

Ersoy El, Mendeş M, Aktan S. Growth curve establishment for American Bronze turkeys. Archiv Tierzucht 2006;49(2):293-299.

Goshu AT, Koya PR. Derivation of inflection points of nonlinear regression curves - implications to statistics. American Journal of Theoretical and Applied Statistics 2013;2(6):268-272.

Lawrence TL, Fowler VR, Novakofsky JE. Growth of farm animals. 3rd ed. Wallingford: CAB International; 2012. p.352.

Mendeş M, Karabayir A, Ersoy IE, Atasoglu C. Effects of three different lighting programs on live weight change of bronze turkeys under semiintensive conditions. Archiv Tierzucht 2005;48(1):86-93.

Mignon-Grasteau S, Beaumont C, Le Bihan-Duval E, Poivey JP, De Rochambeau H, Ricard FH. Genetic parameters of growth curve parameters in male and female chickens. British Poultry Science 1999;40(1):44-51.

Mignon-Grasteau S, Piles M, Varona L, Poivey JP, De Rochambeau H, Blasco $A$, et al. Genetic analysis of growth curve parameters for male and female chickens resulting from selection on shape of growth curve. Journal of Animal Science 2000;78(10):2515-2524.
Pérez-Lara E, Camacho-Escobar MA, García-López JC, Machorro-Samano S, Ávila-Serrano NY, Arroyo-Ledezma J. Mathematical modeling of the native Mexican turkey's growth. Open Journal of Animal Sciences 2013;3:305-310.

Porter T, Kebreab E, Darmani KH, López S, Strathe AB, France J. Flexible alternatives to the Gompertz equation for describing growth with age in turkey hens. Poultry Science 2010;89(2):371-378.

SAS. SAS / STAT user's guide. Version 9.3. 4th ed. Cary: SAS Institute; 2010. $486 \mathrm{p}$.

Sengul T, Kiraz S. Non-linear models for growth curves in Large White turkeys. Turkey Journal of Veterinary and Animal Sciences 2005;29:331337.

Takma C, Özkan S, Akbaș Y. Describing growth curve of turkey toms using Gompertz model. Proceedings of the 22th World's Poultry Congress; 2004 June 8-13; Istanbul. Turquia; 2004. p.154-153.

Tholon P, Queiroz SA. Models for the analysis of growth curves for rearing tinamous (Rhynchotus rufescens) in captivity. Brazilian Journal of Poultry Science 2007;9(1):23-31.

Thornley JHM, France J. Mathematical models in agriculture: quantitative methods for the plant, animal and ecological sciences. Wallingford: CABI Publishing; 2007. 
